\title{
Linkage structure of China's housing market and its risk-defusing capability
}

\author{
Yehui Wang ${ }^{1} \cdot$ Jianxu Liu ${ }^{1,2}$ (I) $\cdot$ Yuxuan Tang ${ }^{3}$. Songsak Sriboonchitta ${ }^{2}$ \\ Accepted: 20 April 2021 / Published online: 30 April 2021 \\ (c) The Author(s), under exclusive licence to Springer-Verlag GmbH Germany, part of Springer Nature 2021
}

\begin{abstract}
There have been many recent fears of severe house-price decreases in some provinces in China causing a nationwide collapse of the housing market. Therefore, this paper aims to clarify the linkage structure of China's housing market and its risk contagion routes. Given monthly data of provincial housing and stock-market capital returns from 2001M01 to 2019M12, on the basis of graph theory, this paper first explores the linkage structure of provincial housing markets. Relying on the linkage structure, this paper then simulates the effect of unexpected negative shocks from the stock market on the probabilities of a housing-market collapse based on the epidemic model. The results show that (i) consistently with practical evidence, the probability of housing-market collapse is relatively high in the southwest of China and (ii) reducing housing-market linkage, such as through a blocking mechanism, to prevent collapse is helpful.
\end{abstract}

Keywords Epidemiological model $\cdot$ Graph theory $\cdot$ Housing market $\cdot$ Linkage

\section{Introduction}

In recent decades, house prices in most developing and developed countries have been sharply increasing. For example, the average house prices in China were 2409.61 and 9208.56 $\mathrm{CNY} / \mathrm{m}^{2}$ in $2001 \mathrm{Q} 1$ and $2019 \mathrm{Q} 4$, respectively $(\mathrm{CNY} 1 \approx$ USD 0.15). This is a $282.16 \%$ nominal inflation during the last 19 years or $14.85 \%$ annual growth on average. However, after 2018, the growth rate of house prices in

Communicated by Vladik Kreinovich.

Jianxu Liu

liujianxu1984@163.com

Yehui Wang

20172152@sdufe.edu.cn

Yuxuan Tang

tangyuxuan@suibe.edu.cn

Songsak Sriboonchitta

songsakecon@gmail.com

1 School of Economics, Shandong University of Finance and Economics, Jinan, China

2 Faculty of Economics, Chiang Mai University, Chiang Mai, Thailand

3 International Development Cooperation Academy, Shanghai University of International Business and Economics, Shanghai, China
China was significantly reduced, and house prices in some provinces severely dropped. The Chinese government and residents are concerned about whether a housing collapse could occur. Drops in house prices can be observed in most recent financial crises, such as the Japanese crisis in 1991, the Southeast Asian financial crisis, and the recent 2007-2008 global financial crisis. In academia, because risk contagion is quite significant in global stock markets, but slight in global housing markets, the stock market has attracted the most attention. However, although correlations of house prices among countries are not significant, there is high correlation on the regional level. The effect of house prices in one region on those of others is known as the "ripple" or "spillover" effect. Meen (1999) provided four possible causes of the ripple effect: migration, equity transfer, spatial arbitrage, and spatial patterns in the determinants of house prices. Two main reasons determine that this research could not rely on or at least fully rely on spatial econometric analysis. First, recent studies showed that the ripple effect is not only driven by geographical distance. For instance, high correlations also appear between highly communicated regions. Second, rather than exploring the fundamental reasons of the ripple effect, this paper forecasts consequences of China's spatial housing markets when a financial crisis reoccurs. Furthermore, the outbreak of COVID-19 is a global pandemic that tremendously affected the economy and finance. It is 
necessary to predict and analyze its influence on housing markets. The earlier that we concentrate on it, the better the chances are to prevent the collapse of the housing market.

\section{Literature review}

Regional house prices usually reflect strong correlations. One of the reasons is that prices in different regions are determined by the same factors, such as interest rate. Thus, changes in these determinants cause comovements of regional house prices. Another important reason is that house prices in one region affect those in other regions, particularly neighboring areas or areas with close economic ties. This distinct spatial pattern is known as the "ripple" or "spillover" effect. At the early stage, houses are immovable and necessary goods mostly for local residents (Meen 1999). Thus, because housing markets are relatively segregated, the ripple effect is not significant. With economic development, an increasing number of residents choose to work, live in, and invest in other regions. Their choices result in regional house prices tending toward convergence (Clapp et al. 1995; Dolde and Tirtiroglu 1997). Evidence suggests that the ripple effect is both negatively correlated with the geographical distance between two regions (Holmes et al. 2011), even across national boundaries (Fereidouni et al. 2016), and highly related to economic ties. For example, the housing prices of metropolitan cities have relatively higher correlation compared to those of rural areas (Van Dijk et al. 2011).

The comovement of stock-market indices is usually called the linkage effect (Forbes and Chinn 2004). Compared with the ripple effect observed from the housing market, the linkage effect of the stock market shows much weaker geographic characteristics. In light of this, the ripple effect can be regarded as special linkage, particularly observed in spatial housing markets. Technically, there are many ways to measure linkage (or connection), but two categories are basically more popular. First, a linkage is measured through related variables such as bilateral import and export trade volumes, immigration, and cross-regional investments, but there is unfortunately little in the literature and few data about this, especially for housing issues (Forbes and Chinn 2004). Second, the linkage is measured through complex network methods, and especially graph theory (Silva and Zhao 2016). Graph theory is good in measuring relations among individuals, such as interpersonal relationships among all football players in a football team. The weight matrix can be calculated by many methods such as Pearson's correlation, Granger causality, ARCH/GARCH-type models, and Copula models (Kenourgios 2014; Kullmann et al. 2002; Liu and Tse 2012; Xiao et al. 2020; Zhang et al. 2010). In addition, two more useful methods need to be introduced. The minimum/maximum spanning tree (MST) method (Silva and
Zhao 2016) is used to effectively retain important relations and remove interference relations. For example, Missio and Watzka (2011) used the MST method to demonstrate the network characteristics of stock markets in EU21 countries. Kamada-Kawai's automatic layout algorithm (Kamada and Kawai 1988) was designed for graph theory and is a method to transfer abstracted algebraic matrix relations to a vivid tree structure diagram.

The relation between housing markets and financial markets is still academically unclear. One of the reasons is that the causal effect between housing and stock markets varies in different countries (Meen et al. 2016). Lee et al. (2017) researched the causal effect between the Australian housing and stock markets, and found that a causality transmission was running from house prices to stock prices before the recent global financial crisis (GFC), but stock prices appeared to lead house prices after the crisis. Gokmenoglu and Hesami (2019) studied the causal relations between the two markets in Germany and found strong reciprocal causation. Wang et al. (2017) focused on the relation between the two markets in Taiwan, but found that there was no causal effect between them. Guo et al. (2011) investigated causal relations among house prices, stock prices, oil prices, and credit prices, and found very complicated effects. Guo et al. also indicated that 2007 is a breakpoint where the structure of the entire market was changed before, during, and after the GFC.

The epidemiological model was originally employed in forecasting the transmission speed, scope, and route of infectious diseases for the purpose of evaluating policy effectiveness. The epidemiological model mainly includes the susceptible-infectious SI, SIR, SIRS, and SEIR models (S = susceptible; $\mathrm{I}=$ infectious; $\mathrm{E}=$ exposed $; \mathrm{R}=$ recovered) (Hethcote 2000). In recent years, the epidemiological model has been used in finance (Peckham 2013), especially the stock market, to simulate how a financial crisis spreads across countries on the basis of network relations estimated by graph theory (Demiris et al. 2014; Korobeinikov 2009; Lee et al. 2011). The key advantage is that, compared with other methods (Liu and Liu 2019; Parray et al. 2020), it is not necessary to know what the fundamental reasons are and why the crisis can spread from one country to another. We only need to estimate their directed relations by graph theory through their prices changes and predict future situations by the epidemic model.

In light of this entire discussion, this paper provides the first attempt to calculate the direct linkage structure among China's 30 provincial housing markets by graph theory in the time and space dimensions. Then, the characteristics of China's housing market are statistically explored. Unlike studies that focus on causal effects, this paper simulates the spread routes and consequences of an imaginary financial crisis by the epidemic model. 
Thus, this paper is organized as follows. Section 2 summarizes the related studies and shows the research targets and structure of this paper. Section 3 describes the data and model. Section 4 discusses the linkage structure and characteristics of the housing market. Section 5 simulates the consequences of the housing market under a supposed shock of financial market. Conclusions and policy suggestions are drawn in Sect. 6.

\section{Data and methods}

\subsection{Data}

As shown in Table 1, the original dataset comprised three variables: housing expenditure $(H E)$, housing space $(H S)$, and stock price $(S P)$. These three were monthly from 2001M01 to 2019M12. $H E$ and $S P$ are tracked by the Chinese currency (CNY). $S P$, the Shanghai Securities Composite Index (SSCE), is the main financial-market indicator in China. $H E$ and $H S$ are panel datasets including 30 provincial regions excluding Tibet, Hong Kong, and Taiwan since data qualities of these three regions are relatively low. The two housing indices were obtained from the National Statistical Yearbook provided by China's National Bureau of Statistics. $S P$ was obtained from the Wind database, which is provided by the Shanghai Stock Exchange.

House price $(H P)$ was calculated as the ratio of $H E$ and $H S$ times 10,000 for the purpose of standardizing the scale to be $\mathrm{CNY} / \mathrm{m}^{2}$. After that, on the basis of house and stock prices, the continuous-type annual growth rate (capital return) of both was calculated, which is the difference of logarithms between the prices of a month and the same month last year. The housing-capital returns of the 30 provinces are designated as $\left[C R_{1}, C R_{2}, \ldots, C R_{30}\right]$ and the capital return of stock market is designated as [C $\left.R_{31}\right]$ where $C R=\left[C R_{1}, C R_{2}, \ldots, C R_{31}\right]$ is the entire capital return matrix. Therefore, the size of the $C R$ is $31 \times 19 \times 12$ $(i \times t \times m)$, where $i$ is the general notation of individuals, $t$ and $m$ are notations of the year and month, respectively.

\subsection{Methods}

The relations among 31 individuals (30 provincial housing markets and 1 stock market) are captured by a capital return series. For each two individuals, the bilateral relation is measured by Pearson's correlation method (Mantegna 1999). In order to annually reflect the different mutual relations, correlations were computed as shown in Eq. (1). Correlation between two specific individuals $i$ and $j$ at the specific year $t$ is their covariance divided by the product of their standard deviation (root of variance). However, covariance is between $i$ 's 12 returns in year $t$ and $j$ 's 12 returns during the same period, but lagged 1 month. The 1 month lag pattern measures the directed relation from $j$ to $i$ (Zhang et al. 2010). When $i=j$, the computed correlation describes the autocorrelation. Interval $[1,12]$ refers to the 12 months of year $t$, and interval $[0,11]$ refers to the 12 months from last December to November of year $t$.

$\rho_{i, j, t}=\frac{\operatorname{Cov}\left(C R_{i, t,[1,12]}, C R_{j, t,[0,11]}\right)}{\sqrt{\operatorname{Var}\left(C R_{i, t,[1,12]}\right)} \cdot \sqrt{\operatorname{Var}\left(C R_{j, t,[0,11]}\right)}}$.

Correlation was obviously in the $[-1,1]$ domain, where 0 means no relation, positive means that prices tended to move in the same direction, and negative means that prices tended to move in the opposite direction. Thus, for each year $t$, the calculated $\rho$ matrix is described as shown in Eq. (2). Because of the lag, specific correlation can be realized as the directed linkage from housing market $j$ to housing market $i$. For example, when a negative shock occurs at Province 1, this shock immediately affects the housing-capital returns of all provinces (1-31) next month through the first column of the $\rho$ matrix. Then, the negative effect spreads and disappears monthly through the whole $\rho$ matrix.

$$
\rho_{t}=\left[\begin{array}{llll}
\rho_{1,1} & \rho_{1,2} & \cdots & \rho_{1,31} \\
\rho_{2,1} & \rho_{2,2} & \cdots & \rho_{2,31} \\
\vdots & \vdots & \ddots & \vdots \\
\rho_{31,1} & \rho_{31,2} & \cdots & \rho_{31,31}
\end{array}\right]_{t} .
$$

In principle, these linkages can track a real housing-market spillover. However, since there are too many linkages, it is difficult to observe the market structure. Empirically, most linkages are tiny $(\approx 0)$, but some are relatively obvious. Thus, the market structure can be analyzed and explored by graph theory (Silva and Zhao 2016). According to graph theory, necessary elements are added to form the weighted directed cyclic graph. The generalized mathematical form is $G_{t}=\left(V, E, W_{t}\right) \cdot V$ is a set of nodes; thus, it is a $31 \times 1$ matrix $[1,2,3, \ldots, 31]^{\prime}$ representing the number of the 31 individuals. $E$ is called an edge set and is mathematically a $V \times V$ matrix to show the binary relation of $V$, which is the relation between nodes. For example, $E_{1,2}$ means the effect of individual $2\left(V_{2}\right)$ on individual $1\left(V_{1}\right)$. W is also a $V \times V$ matrix, representing the weight of each edge. Here, the weight was set to be $\rho_{i, j, t}$ to show the effect of node $j$ on node $i$ at time period $t$.

Since all the values at column $j$ of matrix $\rho$ are the effects of individual $j$ on all individuals (1-31), the summation of this column can track the outward effect of individual $j$. Similarly, since all values at row $i$ of matrix $\rho$ are the effects of all individuals (1-31) on individual $i$, the summation of this row can track the inward effect of individual $i$. In graph theory, the inward and outward effects of node $i$ are indicated by instrength $\left(S^{(\mathrm{in})}\right)$ and out-strength $\left(S^{(\mathrm{out})}\right)$, given by 
Table 1 Data description

\begin{tabular}{llll}
\hline Variable & Full Name & Frequency & Scale \\
\hline$H E$ & Total sales of sold commercialized buildings & Monthly & 100 Million $(\mathrm{CNY})$ \\
$H S$ & Floor space of sold commercialized buildings & Monthly & $10,000 \mathrm{~m}^{2}$ \\
$S P$ & Shanghai Securities Composite Index (SSCE) & Monthly & $\mathrm{CNY}$-based index \\
$H P$ & House prices & Monthly & $H E / H S \times 10,000(\mathrm{CNY})$ \\
$H R$ & Annual housing-capital return (or growth rate) & Monthly & $\ln \left(H P_{i, t, m}\right)-\ln \left(H P_{i, t-1, m}\right)$ \\
$S R$ & Annual financial-capital return (or growth rate) & Monthly & $\ln \left(S P_{t, m}\right)-\ln \left(S P_{t-1, m}\right)$ \\
\hline
\end{tabular}

$i, t, m$ are individual, year, and month, respectively

Eqs. (3) and (4), respectively [see Silva and Zhao (2016)]. The sum of the two strengths for individual $i$ is total strength $\left(S^{(\text {all })}\right)$ given by Eq. (5). Related works suggest that $S^{\text {(in) }}$ and $S^{\text {(out) }}$ can capture whether a market is easily affected by the entire market and whether a market can easily affect the entire market (Wang et al. 2018). Then, $S^{(\text {all) }}$ measures the linkage between the market and the entire market; thus, it is a suitable index with which to show the segregated level of housing markets.

$$
\begin{aligned}
S_{i, t}^{\text {(in })} & =\sum_{j \in V} \rho_{i, j, t} \\
S_{j, t}^{\text {(out) }} & =\sum_{i \in V} \rho_{i, j, t} \\
S_{i, t}^{\text {(all })} & =S_{i, t}^{\text {(in })}+S_{i, t}^{(\text {out })} .
\end{aligned}
$$

Practically, since data were omitted, we preferred to use average strength $(A S)$ as indices in statistical analysis. For example, when Periods 1 and 2 have 10 and 20 observations, respectively, the strength of the former should be much smaller than that of the latter. In order to avoid the influence of the number of observations, average strength $\left(A S_{t}\right)$ is derived as the ratio of the strength to its observation $(n)$ given by Eq. (6) [see Silva and Zhao (2016)]. In addition, since the effective number of nodes $V$ always generate square matrix $W$, the number of effective outward links $\left(n_{i, t}^{\text {(out) }}\right)$ and the number of effective inward links $\left(n_{i, t}^{(\mathrm{in})}\right)$ should be the same for individual $i$.

$$
\begin{aligned}
& A S_{i, t}^{(\text {in })}=S_{i, t}^{(\text {in })} / n_{i, t}^{\text {(in })}=S_{i, t}^{(\text {in })} / n_{i, t} \\
& A S_{i, t}^{\text {(out) }}=S_{i, t}^{\text {(out) }} / n_{i, t}^{\text {(out) }}=S_{i, t}^{\text {(out) }} / n_{i, t} \\
& A S_{i, t}^{\text {(all })}=S_{i, t}^{\text {(all) }} /\left(n_{i, t}^{\text {(in })}+n_{i, t}^{\text {(out) }}\right)=S_{i, t}^{\text {(all })} /\left(2 \cdot n_{i, t}\right) .
\end{aligned}
$$

For each period $t$, remembering that the linkage matrix is described as Eq. (2), the average strength $(A S)$ of the whole market is the average of correlations given by Eq. (7). Similarly, since provincial housing markets are numbered from 1 to 30 , the average strength of the housing market ( $A S H$ ) is the average of all $30 \times 30$ correlations given by Eq. (8). The average strength of the whole market can also be calculated as the average of either the average inward or outward strength since $A S_{t}=\left(1 / n_{t}\right) \sum A S_{i, t}^{(\text {in })}=\left(1 / n_{t}\right) \sum A S_{i, t}^{(\text {out })}$.

$$
\begin{aligned}
A S_{t} & =\frac{1}{n_{t} \times n_{t}} \sum_{i=1}^{n_{t}} \sum_{j=1}^{n_{t}} \rho_{i, j, t} \\
A S H_{t} & =\frac{1}{30 \times 30} \sum_{i=1}^{30} \sum_{j=1}^{30} \rho_{i, j, t} .
\end{aligned}
$$

\section{Housing-market structure and financial-market influence}

\subsection{China's housing market structure and its spillover pattern}

Annual $A S H$ is shown in Fig. 1. There were clear upward and downward changes in $A S H$, and the peak corresponds to the 2007-2008 GFC. In other words, the housing-market structure should have tremendously changed during the recent GFC. After the GFC, especially after 2012, the ASH series was relatively stable. The second subgraph of Fig. 1 shows the national housing- and stock-market capital returns. The two series had significant negative correlation before 2007, positive correlation from 2008 to 2011, and no significant correlation after 2012. In addition, some studies supported considering the time after 2012 as a postcrisis period (Cotter et al. 2011; Guo et al. 2011). This evidence suggests that the recent housing-market structure is relatively stable and should be estimated by data from 2012 to 2019 rather than from the entire sample period.

Now, the sample period is from $2012 \mathrm{~m} 01$ to $2019 \mathrm{~m} 12$, and all indices given by Eqs. (1)-(8) were recalculated. Previous annual time notation $t$ now becomes interval [2012, 2019], referring to the "recent" housing-market linkage structure. The directed linkage matrix $\left(\rho_{[2012,2019]}\right)$ was calculated and is given in Tables 2 and 3. 

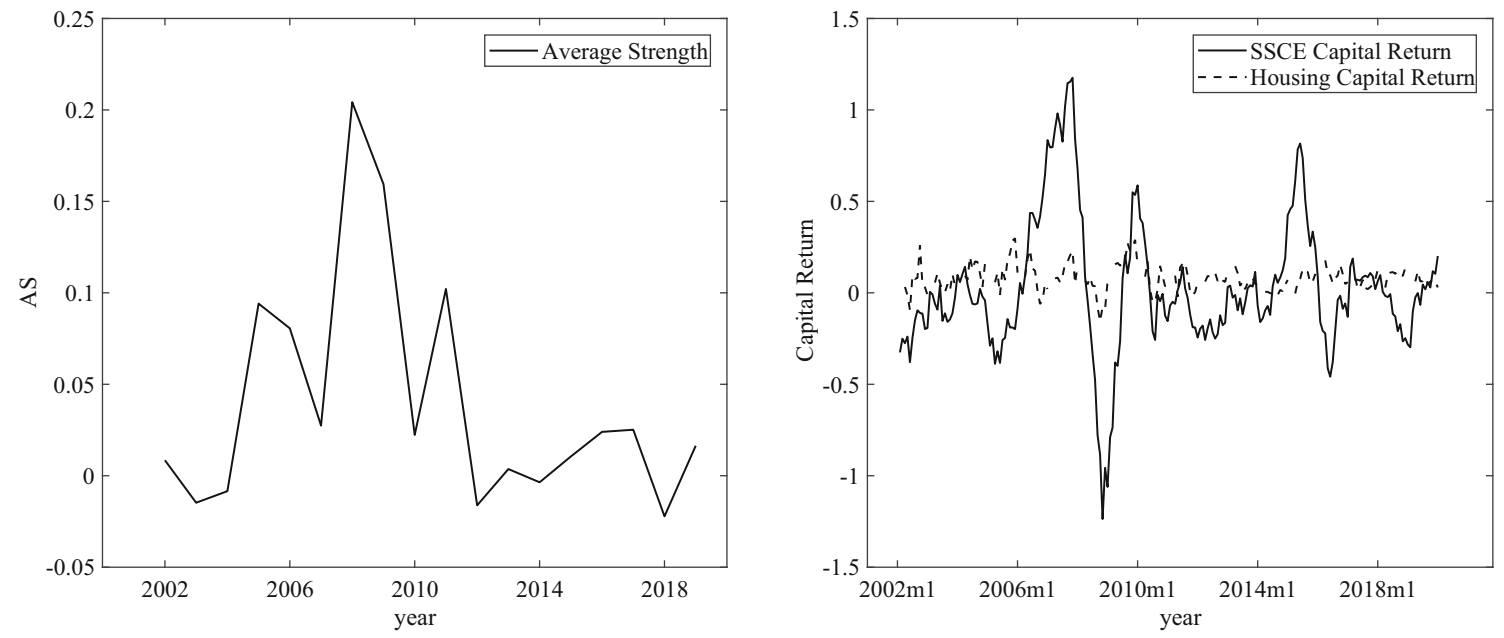

Fig. 1 (left) Average strength of housing market (ASH); (right) capital returns 2002-2019

Tables 2 and 3 show obviously massive values, but most correlations were quite tiny. In order to clarify the market linkage structure, significant linkages should be selected and insignificant linkages should be removed. The minimum/maximum spanning tree (MST), a method from machine learning, can be applied for this purpose. More specifically, MST aims to connect all individuals $(n)$ by the fewest connections $(n-1)$ as a whole network without any cycles, but with the minimum/maximum possible total weight. The MST matrix is derived from the commonly used Kruskal algorithm (Kruskal 1956). The select linkages of the MST matrix can be allocated on map, as shown in Fig. 2; allocations of individuals can be also derived from the Kamada-Kawai automatic layout algorithm (Kamada and Kawai 1988), shown in Fig. 3.

In Fig. 2, all the selected linkages are straight lines with an arrow from the location of province $j$ to the location of province $i$ to show the directed linkage effect. Positive linkages are marked by green, and negative linkages are marked by red. First, as we expected, most significant linkages were positive. The purpose of providing this cartographic MST housing-market linkage structure is to check whether the linkage structure of China's housing market had an intuitive geographic spillover pattern. If the spatial spillover effect is significant, the linkage is more significant for regions closer together. Then, the network reflects a neighborhoodto-neighborhood tree structure, for instance, from the capital city to border regions, or from the southeast to the northwest. The geographic spillover effect was clearly not significant or at least not the main cause of the spatial pattern.

Instead of the geographic characteristics, Kamada-Kawai's automatic layout algorithm (Kamada and Kawai 1988) was employed to explore the characteristics of the network. Simply speaking, the Kamada-Kawai's algorithm can automatically put higher-linkage individuals closer. This method can intuitively indicate whether a region is in the center or edge of a network. Figure 3 shows a clear tree structure; however, the geographical pattern is still insignificant. This linkage structure also cannot be uniquely explained by demographic and economic features. Therefore, it is not appropriate to analyze the structure of China's housing market by standard spatial econometric models.

Although evidence does not support the view that China's provincial housing markets have a regular geographic, demographic, and economic-spillover pattern, the particular linkages shown by Tables 2 and 3 are large enough to generate a very special spillover pattern. The housing capital return of each province in this period is a function of the capital returns of all provinces during last period. Mathematically, the housing capital-return matrix $\left(\left[C R_{1}, C R_{2}, \ldots, C R_{30}\right]^{\prime}\right)$ of time $t$ is a function of the linkage matrix and the housing capital-return matrix of time period $t-1$. It is quite similar to a first-order vector autoregressive process (VAR(1)), but it is very hard to identify whether this mathematical system is stationary. Indeed, the Markov chain in the model is focused on this issue. If the system is stationary, in principle, the effect of exogenous shocks disappears over time. Then, the housing-market structure can defuse, for example, the influence of a financial crisis. If the system is not stationary, panic could be propagated like infectious diseases along the housing-market linkage network. One of the issues is that capital returns could be stationary in some provinces and nonstationary in other provinces. However, stationarity and other mathematically and statistical properties are not our interest. We are interested in (i) the economic meanings and characteristics of the linkage structure, (ii) the predictive ability of this network system, and (iii) the consequences of a hypothetical and unobserved negative shock. 


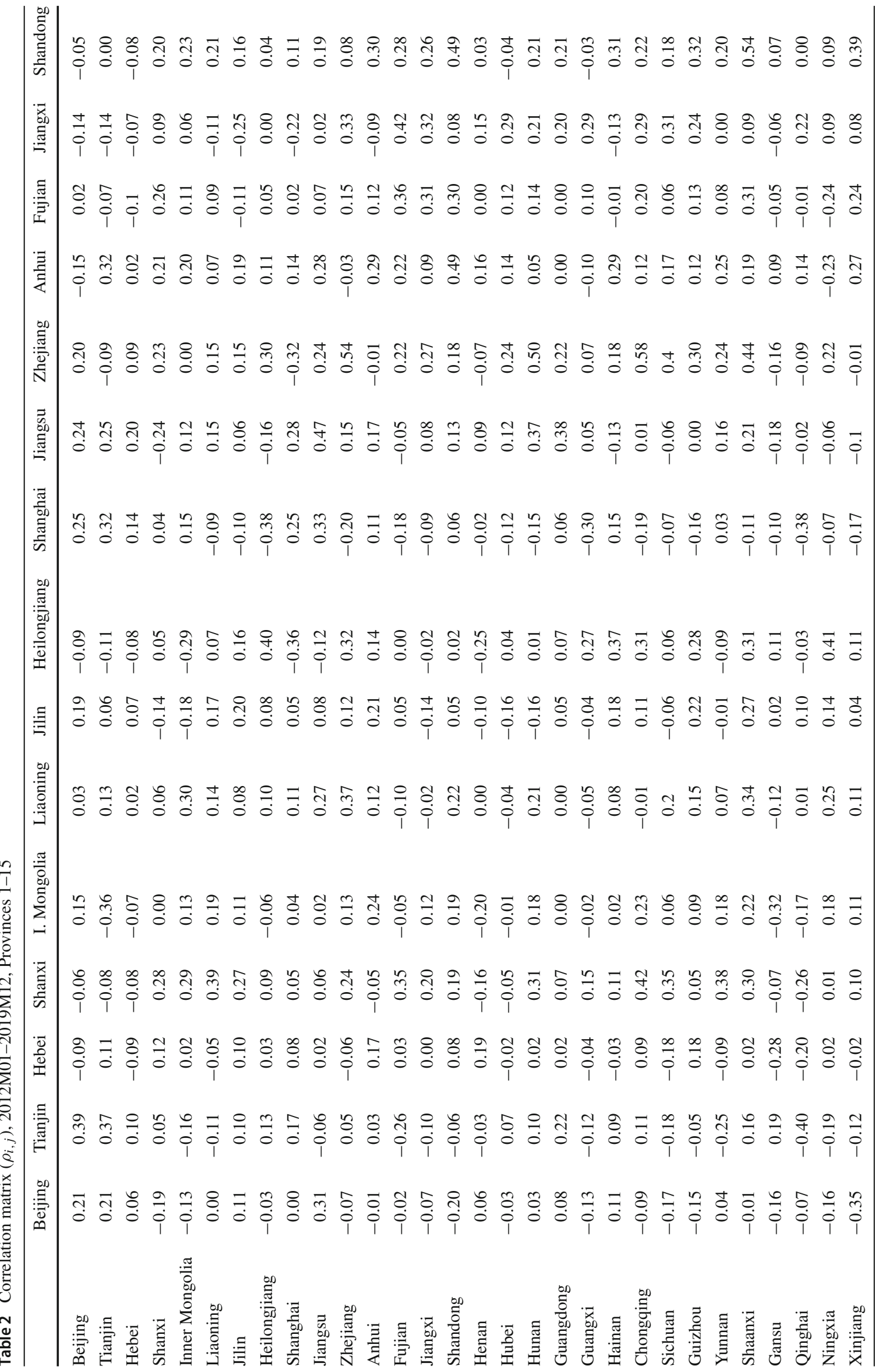




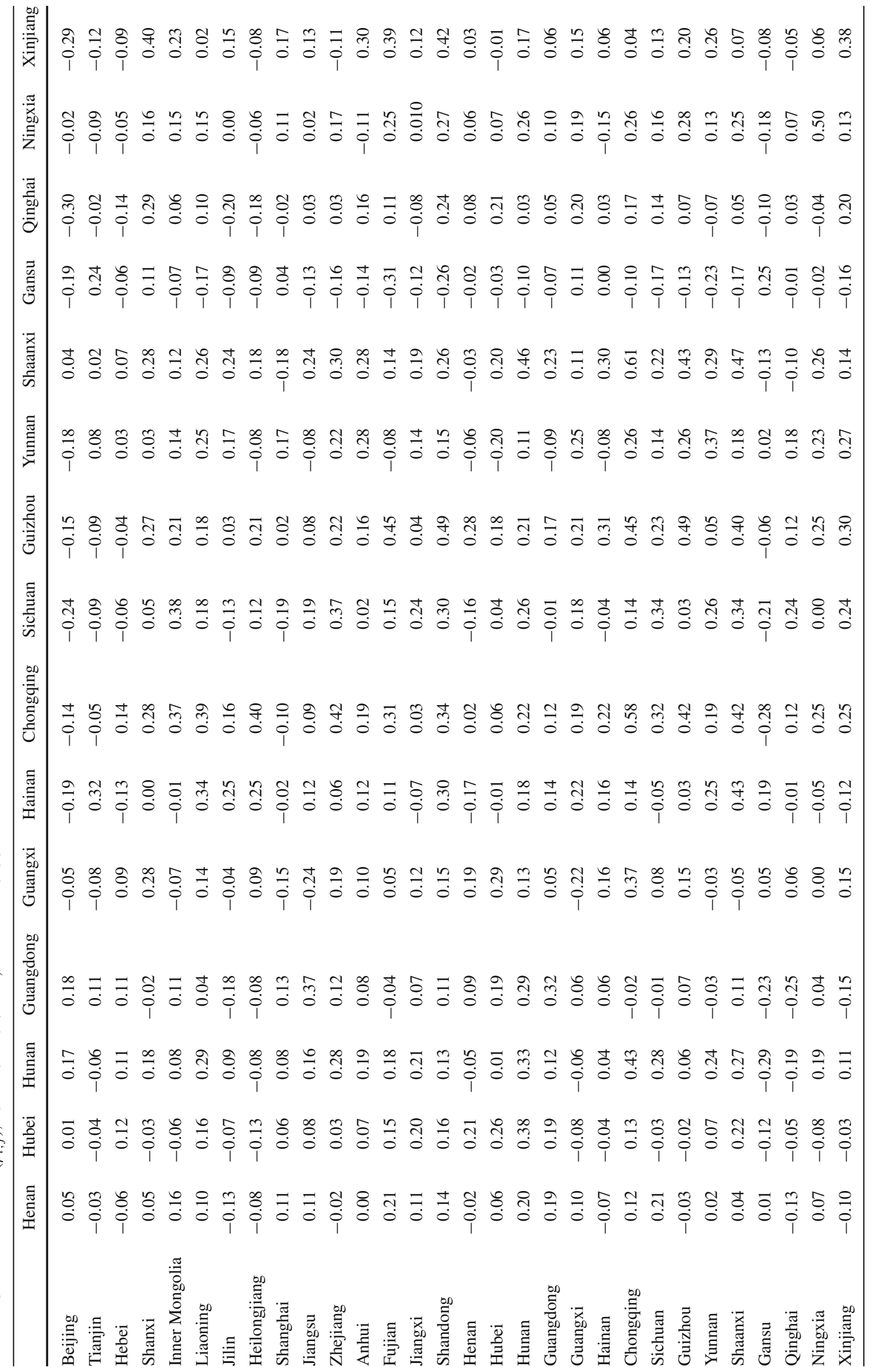




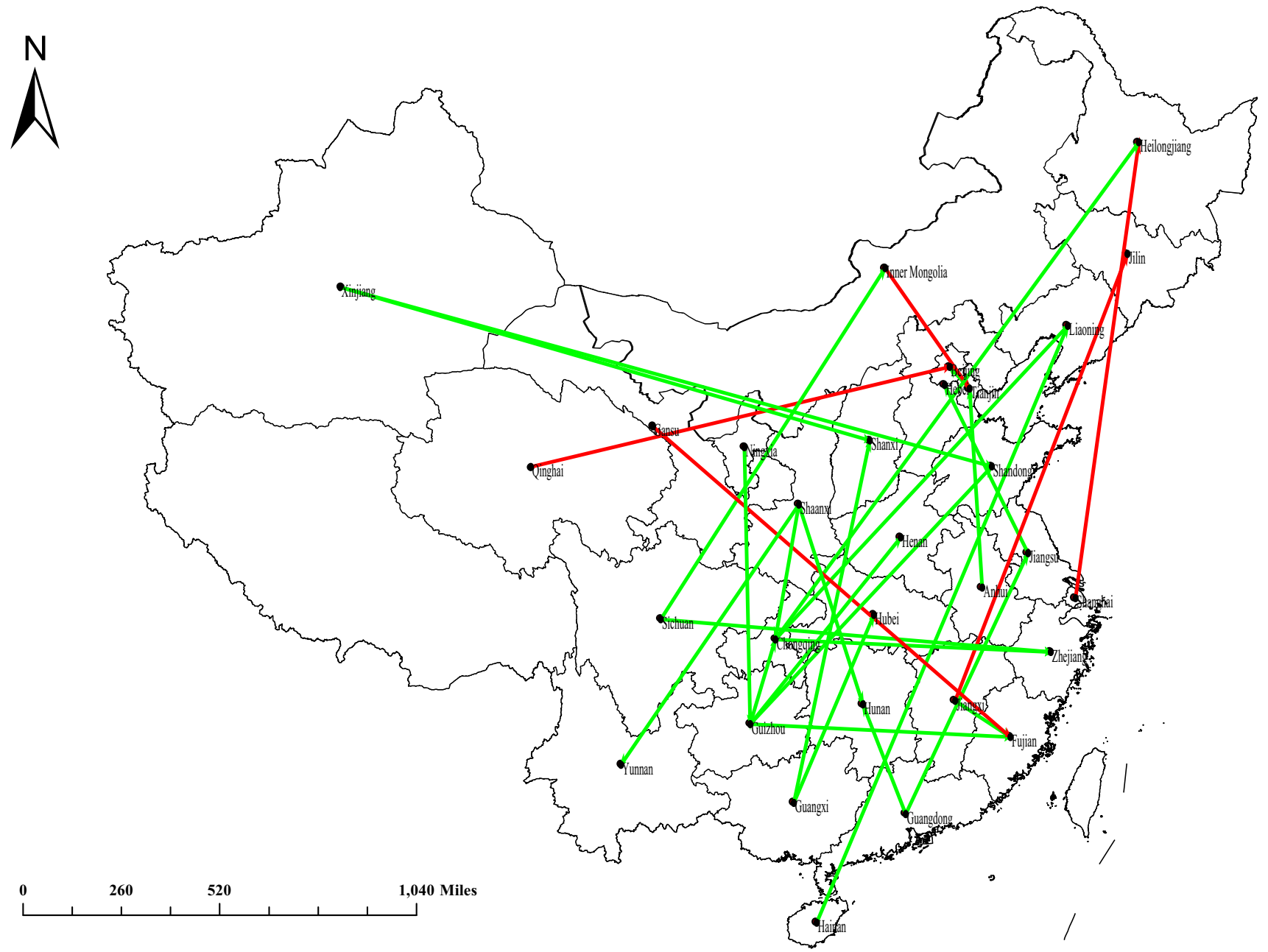

Fig. 2 Cartographic minimum/maximum spanning tree (MST) linkage structure of China's housing market, 2012M01-2019M12

\subsection{Housing-market characteristics and stock-market influence}

In order to understand the characteristics of the linkage structure of China's housing market, and the relations between housing and financial markets, several indices were calculated. Table 4 provides 7 indicators. The first two columns are the mean and standard deviation of the housing capital return. Columns 3 to 5 are the inward, outward, and total average strength of the housing market. These can track the linkage effect of each housing market. Column 6 is the directed linkage from stock market to housing market, and Column 7 is the directed linkage from each housing market to stock market. Correlations among these 7 indicators were calculated and are given in Table 5.

First, correlation among $A S H^{(\text {in) }}, A S H^{(\text {out })}$, and $A S H^{(\text {all })}$ was significantly high. Since $A S H^{(\text {all })}$ is the average of the former two, its high correlation was undoubtedly caused by the high correlation between the two former indices. High correlation between $A S H^{(\text {in) }}$ and $A S H^{(\text {out })}$ is common, meaning that these housing markets had no significant difference in dominating force, or they were of a similar hierarchy. Significant difference can be clearly observed in the network of the global stock market. The outward effect of developed countries is greater than their inward effect is, and the inward effect is much higher in some developing countries. One of the reasons of the hierarchy phenomenon is that affecting others means more dominating force, but to be affected by others means less dominating force. Thus, China's provincial housing markets have no more incentives to compete with or dominate each other. This might be the reason why the spatial spillover is distinct in countries like the US and the UK (Alexander and Barrow 1994; Holmes et al. 2011) but is not significant in China.

Second, the three average strengths were negatively correlated with both the mean and standard deviation of housing returns. On the basis of financial theories, it is quite common that high-return assets usually have high risks (volatilities). Negative correlations imply that returns and risks are relatively high in relatively isolated housing markets, and returns 


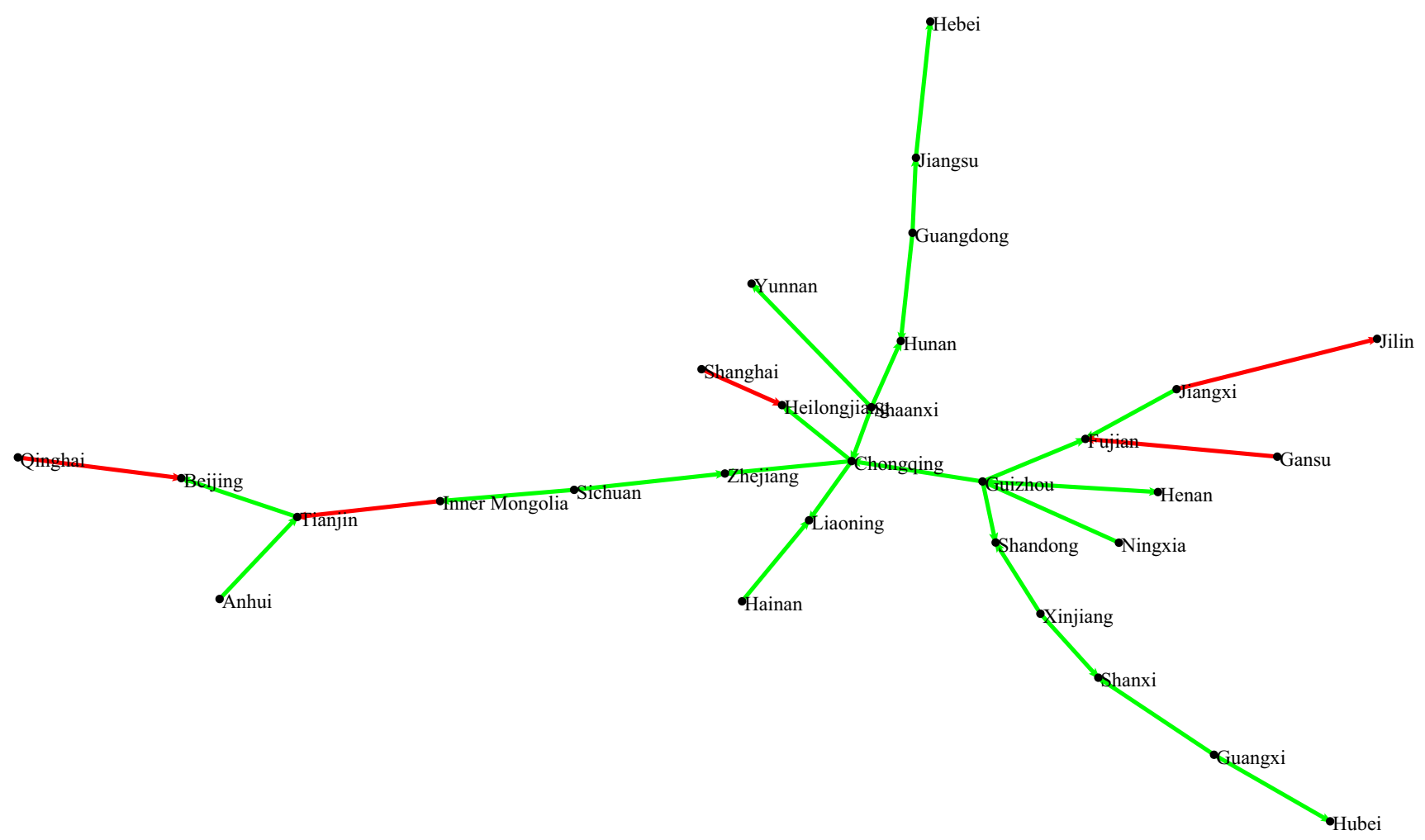

Fig. 3 Abstract MST linkage structure of China's housing market, 2012M01-2019M12

and risks are relatively lower in relatively connected housing markets. This indicates the good side of a high housingmarket linkage, that is, it can effectively reduce returns and risks of housing investment. Both high returns and risks of housing are harmful. High housing returns attract funds flowing from the stock market to the housing market, and economic vitality is then restrained. High volatility means uncertain payment or yield for the renter or landlord, and uncertain costs for companies, both of which are bad for the economy. In light of this, housing-market linkage is usually helpful for price stabilization and risk diversification. This view is consistent with financial methods such as portfolio theory.

On the other hand, despite it not being reflected in the values of Table 5, higher linkages also mean a high probability of shock propagation. Thus, it is possible that, when there is a severe exogenous impact, volatility is relatively high in highly connected markets and relatively low in relatively isolated markets. In order to check this conjecture, we repeated the above process for the period from 2007M01 to 2010M12. The three correlations with the mean become $0.08,-0.02$, and 0.04; the three correlations with St.D. become $0.04,0.07$, and 0.06 . These six values are clearly much smaller, implying much stronger volatility transmission. In addition, decreased correlations were not caused by the decreased linkage effect since, as shown in Fig. 1, the general linkage in this reces- sion period was much higher than that in the later period. Therefore, the linkage structure works in two ways: stronger linkage can help to defuse risks and contribute to transmitting risks.

Third, the six correlations between $\mathrm{StH}$ and $\mathrm{HtS}$ and the three average strengths were significantly negative. In Table 4, most values in Columns 6 and 7 are negative, and most values in Columns 3-5 are positive. Thus, the six significantly negative correlations imply that, for each housing market, if it is strongly and positively connected with the whole housing market, it is easier to be negatively affected by the financial market. This is consistent with summarized results in the literature review, where housing and financial markets were strongly substituted. The substitution effect refers to the case in which the capital returns of one market are more attractive, and funds flow from another to this market; thus, demands and returns change in opposite directions. A highly connected housing market has relatively low volatility and could present more features of the national housing market. The substitution effect should then be more distinct in these highly connected markets. In contrast, relatively isolated markets are isolated because of some of their particularities. Accompanied by relatively high volatility, insignificant correlation is also understandable. 
Table 4 Indicators, 2012M01-2019M12

\begin{tabular}{|c|c|c|c|c|c|c|c|}
\hline Column and Indicator & $\begin{array}{l}\text { (1) } \\
\text { Mean }\end{array}$ & $\begin{array}{l}\text { (2) } \\
\text { St.D. }\end{array}$ & $\begin{array}{l}\text { (3) } \\
A S H^{\text {(in) }}\end{array}$ & $\begin{array}{l}\text { (4) } \\
A S H^{\text {(out) }}\end{array}$ & $\begin{array}{l}\text { (5) } \\
A S H^{\text {(all) }}\end{array}$ & $\begin{array}{l}\text { (6) } \\
\text { StH }\end{array}$ & $\begin{array}{l}\text { (7) } \\
\mathrm{HtS}\end{array}$ \\
\hline Beijing & 0.095 & 0.186 & -0.007 & -0.028 & -0.018 & 0.110 & 0.003 \\
\hline Tianjin & 0.066 & 0.183 & 0.033 & 0.007 & 0.020 & 0.238 & 0.078 \\
\hline Hebei & 0.085 & 0.100 & 0.005 & 0.004 & 0.005 & -0.030 & -0.090 \\
\hline Shanxi & 0.090 & 0.103 & 0.112 & 0.129 & 0.120 & -0.046 & -0.202 \\
\hline Inner Mongolia & 0.063 & 0.114 & 0.089 & 0.044 & 0.067 & -0.153 & -0.231 \\
\hline Liaoning & 0.070 & 0.065 & 0.123 & 0.102 & 0.113 & 0.057 & -0.012 \\
\hline Jilin & 0.051 & 0.140 & 0.049 & 0.049 & 0.049 & 0.155 & 0.105 \\
\hline Heilongjiang & 0.076 & 0.103 & 0.036 & 0.069 & 0.052 & 0.087 & 0.065 \\
\hline Shanghai & 0.094 & 0.221 & 0.022 & -0.033 & -0.005 & 0.070 & -0.050 \\
\hline Jiangsu & 0.073 & 0.082 & 0.111 & 0.090 & 0.101 & -0.262 & -0.271 \\
\hline Zhejiang & 0.055 & 0.088 & 0.142 & 0.173 & 0.157 & -0.073 & -0.132 \\
\hline Anhui & 0.055 & 0.055 & 0.114 & 0.137 & 0.126 & -0.323 & -0.355 \\
\hline Fujian & 0.040 & 0.092 & 0.111 & 0.088 & 0.100 & -0.313 & -0.434 \\
\hline Jiangxi & 0.071 & 0.080 & 0.080 & 0.086 & 0.083 & -0.388 & -0.400 \\
\hline Shandong & 0.075 & 0.056 & 0.180 & 0.169 & 0.175 & -0.203 & -0.275 \\
\hline Henan & 0.073 & 0.067 & 0.010 & 0.046 & 0.028 & -0.068 & -0.187 \\
\hline Hubei & 0.088 & 0.116 & 0.063 & 0.058 & 0.060 & -0.150 & -0.193 \\
\hline Hunan & 0.060 & 0.071 & 0.172 & 0.117 & 0.144 & -0.138 & -0.246 \\
\hline Guangdong & 0.075 & 0.067 & 0.105 & 0.054 & 0.080 & -0.054 & -0.237 \\
\hline Guangxi & 0.066 & 0.093 & 0.057 & 0.065 & 0.061 & -0.131 & -0.053 \\
\hline Hainan & 0.070 & 0.166 & 0.085 & 0.092 & 0.089 & 0.057 & 0.012 \\
\hline Chongqing & 0.074 & 0.104 & 0.199 & 0.198 & 0.198 & -0.123 & -0.234 \\
\hline Sichuan & 0.053 & 0.073 & 0.102 & 0.097 & 0.099 & -0.367 & -0.285 \\
\hline Guizhou & 0.053 & 0.089 & 0.134 & 0.109 & 0.162 & -0.043 & -0.110 \\
\hline Yunnan & 0.094 & 0.139 & 0.098 & 0.102 & 0.100 & -0.115 & -0.064 \\
\hline Shaanxi & 0.072 & 0.111 & 0.211 & 0.197 & 0.204 & -0.063 & -0.266 \\
\hline Gansu & 0.071 & 0.103 & -0.073 & -0.075 & -0.074 & 0.144 & 0.213 \\
\hline Qinghai & 0.105 & 0.196 & -0.037 & 0.038 & 0.000 & -0.297 & -0.097 \\
\hline Ningxia & 0.053 & 0.084 & 0.071 & 0.103 & 0.087 & 0.189 & 0.118 \\
\hline Xinjiang & 0.067 & 0.110 & 0.076 & 0.104 & 0.090 & -0.337 & -0.274 \\
\hline
\end{tabular}

1. $A S H^{\text {(in) }}, A S H^{\text {(out) }}$, and $A S H^{\text {(total) }}$ are average strengths of the housing markets;

2. $\mathrm{StH}=\rho_{i, 31}$, the linkage from stock market (No. 31) to each housing market (No. i);

3. $\mathrm{HtS}=\rho_{31, j}$, the linkage from each housing market (No. j) to stock market (No. 31)

Table 5 Correlation among indicators, 2012M01-2019M12

\begin{tabular}{|c|c|c|c|c|c|c|c|}
\hline Column and indicator & $\begin{array}{l}(1) \\
\text { Mean }\end{array}$ & $\begin{array}{l}\text { (2) } \\
\text { St.D. }\end{array}$ & 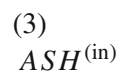 & $\begin{array}{l}\text { (4) } \\
A S H^{\text {(out) }}\end{array}$ & $\begin{array}{l}(5) \\
A S H^{(\text {all })}\end{array}$ & $\begin{array}{l}(6) \\
\text { StH }\end{array}$ & $\begin{array}{l}\text { (7) } \\
\mathrm{HtS}\end{array}$ \\
\hline (1) Mean & 1 & & & & & & \\
\hline (2) St.D. & 0.52 & 1 & & & & & \\
\hline (3) $A S H^{\text {(in) }}$ & -0.36 & -0.48 & 1 & & & & \\
\hline (4) $A S H^{\text {(out) }}$ & -0.35 & -0.50 & 0.89 & 1 & & & \\
\hline (5) $A S H^{\text {(all) }}$ & -0.37 & -0.50 & 0.97 & 0.97 & 1 & & \\
\hline (6) $\mathrm{StH}$ & 0.08 & 0.37 & -0.31 & -0.37 & -0.35 & 1 & \\
\hline (7) $\mathrm{HtS}$ & 0.17 & 0.45 & -0.57 & -0.49 & -0.54 & 0.85 & 1 \\
\hline
\end{tabular}




\section{Simulation analysis}

Housing capital returns affected from one to another market are subject to the linkage matrix $\rho_{[2012 M 01,2019 M 12]}$ over time as given by Eq. (2). This is the same as an infectious disease's spread from one person to another through the human (social) network. The complicated linkage matrix contains the law of recent house-price changes, but since too many values exist in it, it is hard to theoretically derive the overall effects. Simulation analysis is an effective approach to identify housing-market progressions. In fact, the combined use of graph theory and the epidemiological model has already appeared in economics and finance, especially in topics of financial-crisis contagion (Demiris et al. 2014; Korobeinikov 2009; Lee et al. 2011). In light of this, this section simulates the consequences of spatial housing markets under a supposed financial-market crisis in China.

\subsection{Model and key parameters in simulation}

The compartmental models in epidemiology are dynamic models of infectious disease. The models are usually established on a couple of differential equations. Stochastic modeling can also be applied. With the development of the model, an increasing number of factors are taken into account. Here, the standard susceptible-infectious (SI) model is introduced. Equations (9)-(11) form the basic framework of the SI model. Total population $(N)$ is the sum of susceptible/uninfected $(S)$ and infected $(I)$ populations. Since death and cross-regional movement are not considered, changes in susceptible and infected populations are the same. Meanwhile, since infection rate $\beta$ is the new infected population $(d I)$ divided by the uninfected population $(S)$, adjusted by the ratio of percentage of infected population $(I / N)$, the infection rate $(\beta)$ is described as shown in Eq. (11). In addition, other issues such as immunity and incubation period were not taken into account.

$$
\begin{aligned}
& S+I=N \\
& \frac{\mathrm{d} S}{\mathrm{~d} t}+\frac{\mathrm{d} I}{\mathrm{~d} t}=0 \\
& \frac{\mathrm{d} I}{\mathrm{~d} t}=\frac{\beta S I}{N} .
\end{aligned}
$$

For our housing issue, by combining the epidemiological model, especially the SI model, with the Monte Carlo method, we simulated the 30 housing markets for 40 periods (months) in each replication (training). Preliminary testing showed that 200 replications were sufficient to reflect smooth progression. Thus, the structure of the simulated result matrix $(S R M)$ was $30 \times 40 \times 200$. Each space in $S R M$ only had two states, 0 and 1. Corresponding to the uninfected and infected states $(S$ and $I$ ) of the SI model, 0 means normal and 1 means collapse to each housing market $i$ at time $t$ in replication $s$. At time $t=1$, the state of the stock market is 1 , which implies a financial crisis. This financial crisis "infects" the states of the housing markets under the probabilities [e.g., Caccioli et al. (2014)] generated by the linkages $\left(\rho_{i, 31} ; i \in[1,30]\right)$ shown in Table 4 . Then, the states of all 30 housing markets are "infected" by all infected markets, period by period, under probabilities generated by the linkages $(\rho)$ shown in Tables 2 and 3. Thus, compared to the standard SI model, our simulation has three main differences. (i) The standard infection rate of the SI model has a fixed value, but our infection rates were different from market to market. (ii) When the state of the causal market is 1, high linkage refers to high probability rather than "absolutely contagious." (iii) Since stochastic modeling, simulated results are not same in each replication. Thus, the average state of all replications for each $i$ and $t$ is calculated and defined as $S P M_{i, t}$. This average can be regarded as the probability that the housing market collapses. For instance, despite the state of the Beijing housing market only being able to be 0 or 1 in each replication, when 70 states are 1 , and 130 are 0 in all 200 replications, the probability of housing collapse is $70 / 200=0.35=35 \%$. Furthermore, $\beta$ here is used as an amplifier of the linkage matrix. Benchmark $\beta$ was set to be 1 , which means original linkages. We also employed other larger and smaller values of $\beta$ to check the consequences of greater or lesser entire housing market linkages.

\subsection{Spatial housing-market consequences}

$S P M$ indicates the simulated probability of housing-market collapse in the 30 provinces during 40 periods. Recently, the National Bureau of Statistics provided data of housing expenditure $(H E)$ and housing size $(H S)$ for April 2020 (see Table 1 for more details). The house prices in April 2020 of all 30 provinces $\left(H P_{[1,30], 2020,4}\right)$ were calculated. Combining with provincial house prices in December $2019\left(H P_{[1,30], 2019,12}\right)$, housing capital returns $\left(C R_{[1,30]}\right)$ from 2019M12 to 2020M04 can be derived. By using these new provided data, we can practically check the quality of the simulated probabilities $(S P M)$. First, the correlations between $C R_{[1,30],(2019 \mathrm{M} 12-2020 \mathrm{M} 04)}$ and $S P M_{[1,30], t}$ of each simulated period were calculated and are given in Fig. 4. Generally, newly released housing capital returns are significantly and negatively correlated with the simulated $S P M$ over the first 24 periods. It is reasonable that housing capital returns are relatively low or even fall at provinces for which the simulated probability of collapse is high. The lowest correlation between the new $C R$ and the $S P M$ is -0.45 at Period 6. Since (i) house prices are usually affected by many economic factors [e.g., Wang et al. (2020)], but our SPM was only derived from the linkage network; and (ii) $C R$ are capital returns, but $S P M$ are simulated probabilities, corre- 


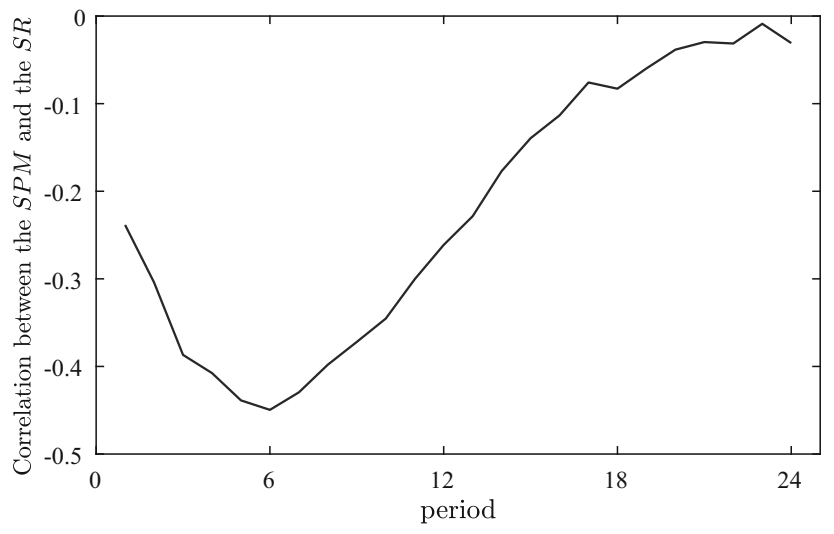

Fig. 4 Correlation between $C R_{[1,30],} \quad(2019 \mathrm{M} 12-2020 \mathrm{M} 04)$ and $S P M_{[1,30], t}$

lations between the two were much greater than what we had predicted.

Given this largest absolute correlation between $S P M$ at Period 6 and the new $C R, S P M_{6}$ and the new $C R$ are separately mapped and given by Figs. 5 and 6 . Figure 5 shows that the simulated probability of housing-market collapse is relatively high in the southwest. Figure 6 shows that house prices in the southwest of China were seriously decreased at the beginning of 2020. Why is there high similarity between recent housing capital returns and simulated probabilities under a supposed financial crisis? This may have been caused by the 2019 Supertyphoon Lekima or COVID-19. This study cannot give an answer to this question yet; however, we suggest to focus on provinces such as Ningxia and Shaanxi, of which recent housing capital returns were high, but the simulated probability of housing-market collapse is also high. It is very possible that the downward trend of those housing markets has not yet emerged, and we aim to further track price changes. All in all, evidence such as the extreme high correlation between practical and simulated values discussed in this subsection suggests that the simulated probability of housing-market collapse is relatively accurate.

\subsection{Dynamic housing-market consequences}

The simulated probability matrix $\left(S P M_{i, t}\right)$ has both spatial $(i)$ and time $(t)$ dimensions. For the purpose of reflecting the dynamic changes of SPM, ASPM was calculated. ASPM is the national average of $S P M$, and each element $A S P M_{t}$ is equal to $(1 / 30) \cdot \sum_{i=1}^{30} S P M_{i, t}$. The standard $A S P M$ is given by the solid line in Fig. 7. As discussed above, we also examined the influence of different overall linkages through different $\beta$. On the basis of preliminary tests, simulated results were quite sensitive to parameter $\beta$; thus, we conducted three other $\beta(0.5,1.5,2.0)$, shown in Fig. 7.

The probability of housing collapse first sharply rose and then dramatically fell. The solid line was clearly quite sim-

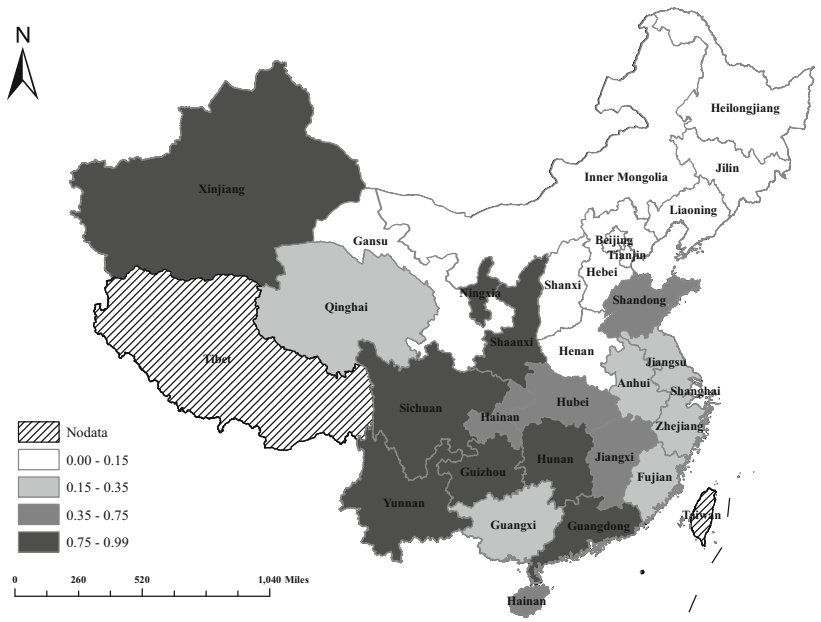

Fig. 5 Map of simulated probabilities of housing collapse $\left(S P M_{[1,30]}\right)$ at Period 6)

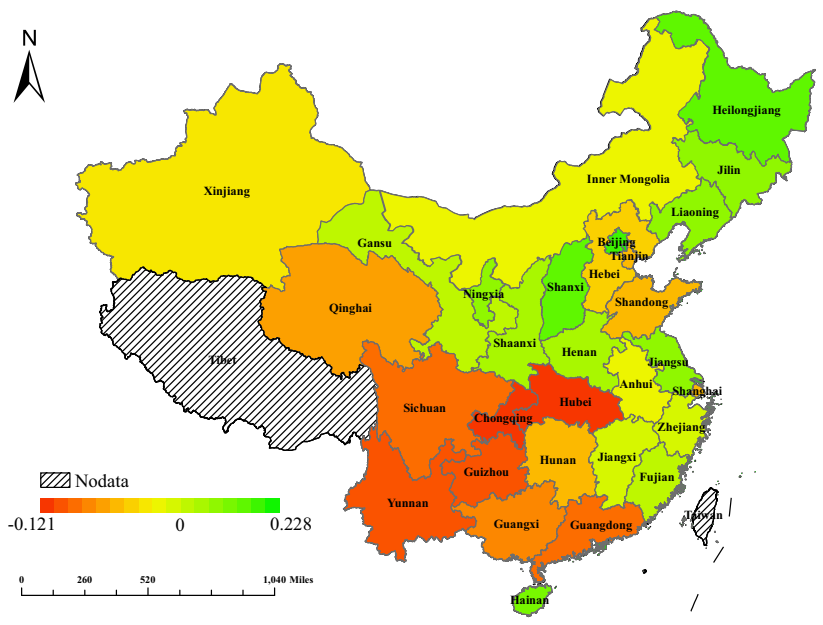

Fig. 6 Map of practical housing-capital returns $\left(C R_{[1,30]}\right)$ from 2019M12 to 2020M04

ilar to that in the infected population of epidemic diseases. Meanwhile, since cure, death, and immunization were not taken into account in the SI model, it had no force of reduction. However, the solid line reflects an inbuilt mechanism of defusing unexpected market volatilities. This mechanism was constructed by specific market linkage structure $\rho_{i, j}$ given in Tables 2 and 3. Negative shock is slowly "digested" by the segregated regions; thus, unexpected shocks cannot cause a nationwide housing collapse. In other words, the housing market itself can defuse external risks, although this risk-defusing process needs approximately 1.5 years (18 months/periods).

The comparison between solid and dotted lines indicates that risk-defusing capability is negatively related to the general strength of the linkage structure of the housing market. For instance, Fig. 7 shows that, if the housing-market linkage rises by $50 \%$, the probability of housing-market collapse 


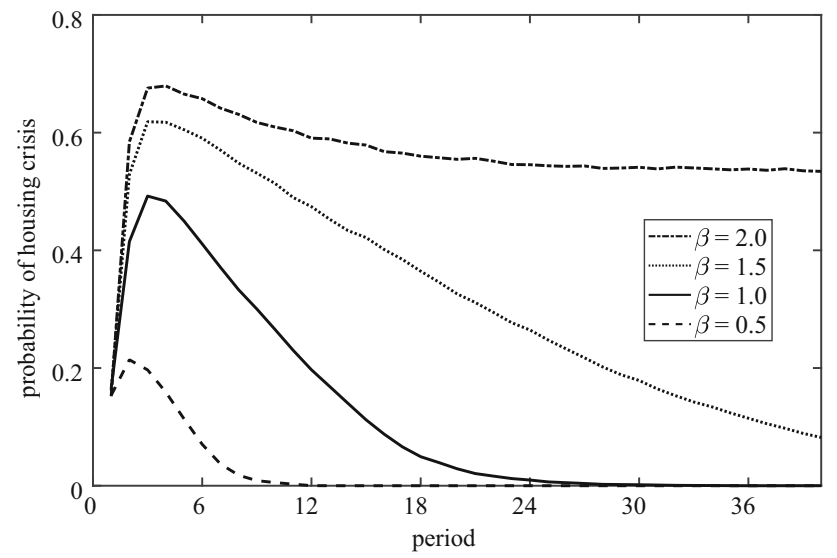

Fig. 7 Simulated probabilities of housing crisis $(A S P M)$

is sharply increased, and risk-defusing capability is much weaker; if housing-market linkage is approximately doubled, risk-defusing capability almost disappears; on the other hand, if overall housing-market linkage decreases by $50 \%$, the probability of housing-market collapse is significantly reduced, but risk-defusing capability (slope) is not significantly changed compared with the solid line. The probability of housing-market collapse is very sensitive to housingmarket linkage. Therefore, the above results suggest that the recent linkage structure of China's housing market is relatively large. It is necessary to weaken the housing-market linkage to avoid housing-market collapse.

\section{Conclusion and policy suggestion}

This paper first revealed the network structure of China's provincial housing market by graph theory. Results suggested that the housing-market linkage structure is not determined by either geographic or economic factors. The results of some indicators suggested that both the mean and volatility of housing capital returns were relatively high in relatively isolated provinces; in contrast, both mean and volatility of housing capital returns were relatively low in relatively connected provinces. Results also suggested that the housing markets of highly connected provinces are more easily negatively affected by financial-market shocks. Then, the probability of housing-market collapse was simulated under a supposed financial-market crisis through the combination of an epidemiological model and the Monte Carlo method. Simulated results showed that (i) the probability of housing-market collapse is relatively high in southwest China, consistent with practical data; (ii) housing markets have an inbuilt risk-defusing capability, and this capability is negatively related to the overall strength of the linkage network; (iii) China's recent housing market has relatively high overall linkage. Therefore, on the basis of this paper's work, we put forward the new point view that unrelated fluctuations in house prices are not bad or good in avoiding housing collapse. For example, if all housing markets have extremely high correlations, an unexpected negative shock such as the GFC causes panic and selling in the housing market, and then spreads across the country like an epidemic.

Therefore, policy suggestions are given. First, the isolation mechanism, also known as the blocking mechanism in finance, is necessary for housing markets. For example, such a policy can be specified as houses that can only be sold to local residences rather than tourists and refugees. Second, more attention should be paid to housing markets of which the simulated probability of housing-market collapse is relatively high. Third, in housing finance, the government should control cross-regional housing investment or arbitrage behavior to reduce nationwide housing-market linkage in order to prevent house-price collapse.

There are a few limitations in our study. Although, as far as we know, this paper is initial work on the linkage structure of China's housing market, and simulates the spatial and dynamic consequences, more economic factors need to be considered and analyzed. The effects of these economic factors, such as interest rates and inflation rates, on house prices are worth studying since monetary policies can either stabilize fluctuations in house prices or boost the scopes and the probabilities of housing-market collapse.

Acknowledgements This research was supported by Shandong Social Science Planning Research Project (China; Grant Number 19DTJJ02) and the Centre of Excellence in Econometrics at Chiang Mai University.

Author Contributions Y.W. and J.L. designed the research; Y.W., J.L., Y.T., and S.S. conducted the review and editing; S.S. provided funding acquisition, project administration, and resources; and Y.W. and Y.T. wrote the paper.

\section{Declarations}

Conflict of interest The authors declare that there is no conflict of interest regarding the publication of this paper.

Ethical approval This article does not contain any studies with human participants or animals performed by any of the authors.

\section{References}

Alexander C, Barrow M (1994) Seasonality and cointegration of regional house prices in the UK. Urban Stud 31(10):1667-1689

Caccioli F, Shrestha M, Moore C, Farmer JD (2014) Stability analysis of financial contagion due to overlapping portfolios. J Bank Finance 46:233-245

Clapp JM, Dolde W, Tirtiroglu D (1995) Imperfect information and investor inferences from housing price dynamics. Real Estate Econ 23(3):239-269

Cotter J, Gabriel S, Roll R (2011) Integration and contagion in US Housing Markets. arXiv preprint arXiv:1110.4119 
Demiris N, Kypraios T, Vanessa Smith L (2014) On the epidemic of financial crises. J R Stat Soc Ser A (Statistics in Society) 177(3):697-723

Dolde W, Tirtiroglu D (1997) Temporal and spatial information diffusion in real estate price changes and variances. Real Estate Econ 25(4):539-565

Fereidouni HG, Al-Mulali U, Lee JY, Mohammed AH (2016) Dynamic relationship between house prices in Malaysia's major economic regions and Singapore house prices. Reg Stud 50(4):657-670

Forbes KJ, Chinn MD (2004) A decomposition of global linkages in financial markets over time. Rev Econ Stat 86(3):705-722

Gokmenoglu K, Hesami S (2019) Real estate prices and stock market in Germany: analysis based on hedonic price index. Int J Hous Mark Anal. https://doi.org/10.1108/IJHMA-05-2018-0036

Guo F, Chen CR, Huang YS (2011) Markets contagion during financial crisis: a regime-switching approach. Int Rev Econ Finance 20(1):95-109

Hethcote HW (2000) The mathematics of infectious diseases. SIAM Rev 42(4):599-653

Holmes MJ, Otero J, Panagiotidis T (2011) Investigating regional house price convergence in the United States: evidence from a pair-wise approach. Econ Modell 28(6):2369-2376

Kamada T, Kawai S (1988) Advanced graphics for visualization of shielding relations. Comput Vis Gr Image Process 43(3):294-312

Kenourgios D (2014) On financial contagion and implied market volatility. Int Rev Financ Anal 34:21-30

Korobeinikov A (2009) Financial crisis: an attempt of mathematical modelling. Appl Math Lett 22(12):1882-1886

Kruskal JB (1956) On the shortest spanning subtree of a graph and the traveling salesman problem. Proc Am Math Soc 7(1):48-50

Kullmann L, Kertész J, Kaski K (2002) Time-dependent crosscorrelations between different stock returns: a directed network of influence. Phys Rev E 66(2):026125

Lee KM, Yang JS, Kim G, Lee J, Goh KI, Kim IM (2011) Impact of the topology of global macroeconomic network on the spreading of economic crises. PLoS ONE 6(3):e18443

Lee MT, Lee CL, Lee ML, Liao CY (2017) Price linkages between Australian housing and stock markets. Int J Hous Mark Anal. https:// doi.org/10.1108/IJHMA-05-2016-0037

Liu R, Liu L (2019) Predicting housing price in China based on long short-term memory incorporating modified genetic algorithm. Soft Comput 23(22):11829-11838

Liu XF, Tse CK (2012) A complex network perspective of world stock markets: synchronization and volatility. Int J Bifurc Chaos 22(06): 1250142
Mantegna RN (1999) Hierarchical structure in financial markets. Eur Phys J B Condens Matter Complex Syst 11(1):193-197

Meen G (1999) Regional house prices and the ripple effect: a new interpretation. Hous Stud 14(6):733-753

Meen G, Mihailov A, Wang Y et al (2016) Endogenous UK housing cycles and the risk premium: understanding the next housing crisis. Technical Reports, Henley Business School, Reading University

Missio S, Watzka S et al (2011) Financial contagion and the European debt crisis. Technical Reports, CESifo Group Munich

Parray IR, Khurana SS, Kumar M, Altalbe AA (2020) Time series data analysis of stock price movement using machine learning techniques. Soft Comput 24:1-9

Peckham R (2013) Economies of contagion: financial crisis and pandemic. Econ Soc 42(2):226-248

Silva TC, Zhao L (2016) Machine learning in complex networks, vol 2016. Springer, Switzerland

Van Dijk B, Franses PH, Paap R, Van Dijk D (2011) Modelling regional house prices. Appl Econ 43(17):2097-2110

Wang GJ, Xie C, Stanley HE (2018) Correlation structure and evolution of world stock markets: evidence from Pearson and partial correlation-based networks. Comput Econ 51(3):607-635

Wang Y, Liu J, Tang Y, Sriboonchitta S (2020) Housing risk and its influence on house price: an expected utility approach. Math Probl Eng 2020:16

Wang YC, Huang R, Nieh CC, Ou HK, Chi M (2017) Integration between real estate market and stock market: evidence from Taiwan. In: 2017 international conference on applied system innovation (ICASI), IEEE, pp 1611-1614

Xiao L, Dhesi G, Ceptureanu EG, Lin K, Herteliu C, Syed B, Ceptureanu SI (2020) Liquidity transmission and the subprime mortgage crisis: a multivariate Garch approach. Soft Comput 24:1-8

Zhang J, Zhou H, Jiang L, Wang Y (2010) Network topologies of shanghai stock index. Phys Procedia 3(5):1733-1740

Publisher's Note Springer Nature remains neutral with regard to jurisdictional claims in published maps and institutional affiliations. 